\title{
Vigilância de fitoterápicos em Minas Gerais. Verificação da qualidade de diferentes amostras comerciais de camomila
}

\author{
Surveillance of phytotherapeutic drugs in the State \\ of M inas Gerais. Q uality assessment of commercial \\ samples of chamomile
}

Maria G. Lins Brandão 1

Noélia Freire 1

Cristina D. Vianna-Soares 2

\footnotetext{
1 Laboratório de

Farmacognosia,

Departamento de Produtos

Farmacêuticos, Faculdade

de Farmácia, Universidade

Federal de Minas Gerais.

Av. Olegário Maciel 2.360,

Belo Horizonte, MG

30180-112, Brasil.

2 Laboratório de

Controle de Qualidade

Departamento de Produtos

Farmacêuticos, Faculdade

de Farmácia, Universidade

Federal de Minas Gerais.

Av. Olegário Maciel 2.360,

Belo Horizonte, MG

30180-112, Brasil.

branlins@oraculo.lcc.ufmg.br
}

Abstract Marketing of medicinal plants and phytotherapeutic products is spreading all over the world. In order to assess the commercialization of medicinal plants and phytotherapeutic products in the State of Minas Gerais, we identified and tested for the presence of adulterants and active ingredients in 27 samples of chamomile. All the samples consisted of Matricaria recutita flowers, but they were badly fragmented, a result of excessive handling and poor preservation. All samples contained contaminants, and insects were observed in $63 \%$ of the samples sold in drugstores. Only $50 \%$ of the samples in each group had the essential oils needed to produce anti inflammatory activity. Flavonoids and other phenolic constituents with a spasmolytic effect were detected in only $20 \%$ of the samples from each group. Results with chamomile indicated the poor quality with which medicinal plants and phytotherapeutic products are marketed and confirm the need for surveillance of such products in Brazil.

Key words Chamomilla; Herbal Medicine; Medicinal Plants; Health Surveillance

Resumo O comércio de plantas medi cinais e produtos fitoterápi cos encontra-se em expansão em todo o mundo. Uma portaria Iançada recentemente pelo Ministério da Saúde busca regulamentar a produção dos fitoterápi cos comercializados no Brasil. Com o objetivo de contribuir com a farmacovi gi lância deste setor, ini ciamos um programa de avaliação do material fitoterápi co comercializado em Minas Gerais. Foram analisadas 27 amostras de camomila, procedentes de farmácias, ervanarias e mercados, quanto à identidade, pureza e presença dos constituintes ativos. Apesar de todas as amostras serem constituídas da genuína Matricaria recutita, na mai or parte os capítul os florais estavam muito destruídos, conseqüência de manusei o excessi vo ou má conservação. Foram detectados contaminantes em todas as amostras, estando insetos presentes em $63 \%$ daquelas comercializadas em farmácias. Somente cerca de metade das amostras apresentaram os constituintes dos óleos essenciais, necessários à ati vidadeantii nflamatória da planta. Os constituintes fenólicos, de ação espasmolítica, foram detectados em somente cerca de $20 \%$. Os resultados com a camomi la indicam a precari edade com que as plantas medicinais e fitoterápi cos vêm sendo comercializados e confirmam a necessi dade urgente de vi gilância destes produtos no Brasil.

Palavras-chave Chamomilla; Medicina Herbária; Plantas Medicinais; Vigilância Sanitária 
Introdução

O comércio de plantas medicinais e produtos fitoterápicos encontra-se em expansão em todo o mundo em razão de diversos fatores, como o alto custo dos medicamentos industrializados ou o próprio modismo. A má qualidade destes produtos no Brasil, no entanto, é um fato conhecido (Stelfelld, 1955; Farias et al., 1985), e recentemente o Ministério da Saúde (MS) elaborou uma portaria regulamentando os procedimentos para a produção destes medicamentos (MS, 1995). Por outro lado, a atividade de farmacovigilância no País é incipiente, sendo praticamente inexistente para fitoterápicos. Com o objetivo de contribuir neste setor, iniciamos um programa de avaliação dos fitoterápicos comercializados em Minas Gerais. Neste trabalho, descrevemos os resultados obtidos com amostras de camomila, uma planta amplamente conhecida e utilizada.

\section{Material e métodos}

Obtenção das amostras

Foram analisadas 27 amostras comerciais de camomila, procedentes de farmácias e ervanarias de al gumas localidades de Minas Gerais, em paral elo a uma amostra comercializada na Europa (Finlândia). As amostras foram classificadas, segundo suas procedências, em três grupos: (A) sete amostras produzidas por 'raizeiros' e comercializadas em farmácias; (B) 11 provenientes de empresas e comercializadas em farmácias e (C) nove provenientes de empresase comercializadas em mercados e ervanarias. Como procedente de 'raizeiros', foram consideradas amostras produzidas por pequenos produtores, sem registro, que comercializam diretamente seus produtos. Procedentes de empresas, foram consi deradas amostras que apresentavam nos rótulos nomes e endereços dos produtores, incluindo número de CGC.

Todas as amostras foram analisadas através das técnicas preconizadas pelas Farmacopéias Brasileiras 2a Ed. (Farmacopéia, 1959) e 4a Ed. (Farmacopéia, 1988-1996), farmacopéia britânica (British, 1988) e pela literatura especializada restante.

\section{Estudo da identidade}

Cada amostra foi analisada macro e microscopicamente, buscando identificar as características morfológicas descritas na literatura para a espécie.

\section{Análise das impurezas}

\section{- Flores estranhas}

Analisou-se cada amostra com o auxílio de lupa, observando a existência e a quantidade de capítulos de outras plantas. A Farmacopéia Brasileira 2a Ed. exige a ausência deste contaminante.

\section{- M atéria orgânica estranha}

Foi feita a análise de cada amostra buscandose detectar a presença de matérias estranhas à droga, como outras partes da planta (pedúnculos), insetos, bem como os produtos de seu metabolismo. A Farmacopéia Brasileira 4a Ed. admite um máximo de $5 \%$ deste material.

\section{- Cinzas totais}

Consiste na carbonização do material até cinzas. O peso além do limite estabelecido é indicativo da presença de material inorgânico adulterante, como areia, terra ou pedras. As Farmacopéias Brasileiras 2a Ed. e 4a Ed. admitem um máximo de $14 \%$ de cinzas totais.

\section{Presença dos constituintes ativos}

Constituintes ativos foram detectados através de perfis cromatográficos em camada delgada (CCD), utilizando placas revestidas com sílica $\mathrm{G} 60(0,25 \mathrm{~mm}$, Merck) e eluentes e reveladores indicados em Wagner et al. (1984). Após a eluição e revelação, os perfis cromatográficos eram comparados com os descritos por estes mesmos autores. Para a obtenção dos óleos essenciais, $1,0 \mathrm{~g}$ de cada amostra pulverizada foi agitada, a frio, por 15min, com $10 \mathrm{ml}$ de diclorometano. Após filtração, as soluções foram evaporadas a vácuo à temperatura máxima de $30 \circ \mathrm{C}$, recuperadas com tolueno e aplicados nas placas. Para a obtenção dos constituintes fenólicos, 1,0g de cada amostra foi extraída com $10 \mathrm{ml}$ de metanol, por cinco minutos, em banho-maria. Após filtração, o volume foi reduzido e aplicado diretamente nas placas.

\section{Resultados e discussão}

A Tabela 1 apresenta os resultados obtidos por grupos de amostras. $O$ estudo da identidade evidenciou que todas as amostras eram constituídas da genuína Matricaria recutita. Apesar de a farmacopéia brasileira preconizar que a droga deve ser constituída de capítulos florais 
Tabela 1

Relação do número de amostras e respectivas porcentagens, em cada grupo, que se apresentaram dentro dos parâmetros de qualidade descritos nos Códigos O ficiais e na literatura.

\begin{tabular}{|c|c|c|c|}
\hline Parâmetros avaliados & Grupo (A) & Grupo (B) & Grupo (C) \\
\hline Número de amostras & $07(\%)$ & $11(\%)$ & $09(\%)$ \\
\hline Amostras constituídas por capítulos florais de Matricaria recutita & $7(100)$ & $11(100)$ & $9(100)$ \\
\hline Máximo de $25 \%$ de capítulos florais contundidos & $2(28,5)$ & $3(27,2)$ & $0(0)$ \\
\hline Presença de flores estranhas & $2(28,5)$ & $3(27,2)$ & $1(11,1)$ \\
\hline Presença de insetos & $3(42,8)$ & $7(63,6)$ & $4(44,4)$ \\
\hline Pedúnculos de capítulos dentro do limite de $5 \%$ & $0(0)$ & $1(9)$ & $0(0)$ \\
\hline Cinzas totais dentro do limite de $14 \%$ & $7(100)$ & $10(90,9)$ & $9(100)$ \\
\hline Presença dos constituintes ativos dos óleos essenciais & $3(42,8)$ & $6(54,5)$ & $5(55,5)$ \\
\hline Presença das substâncias fenólicas ativas & $2(28,5)$ & $3(27,1)$ & $0(0)$ \\
\hline
\end{tabular}

Grupo $(A)=$ material produzido por 'raizeiro' e comercializado em farmácia;

Grupo $(B)=$ material proveniente de empresa e comercializado em farmácia;

Grupo $(C)=$ material proveniente de empresa e comercializado em mercados e ervanarias.

inteiros, na maior parte das amostras estes se encontravam bastante contundidos (destruídos), indicativo de manuseio excessivo e má conservação. A farmacopéia britânica preconiza um máximo de $25 \%$ de capítulos contundidos para a $\mathrm{M}$. recutita e somente $28,5 \%$ das amostras do grupo (A) e 27,2\% das do grupo (B) incluíram-se em tal limite (British, 1988).

Foram detectadas flores estranhas e insetos (coleópteros, muitas vezes vivos) em todos os grupos de amostras. Apesar de as flores estranhas terem se apresentado como um contaminante menos freqüente que os insetos, a presença de plantas desconhecidas pode se tornar nociva, quando se tratar de material tóxico. Somente uma amostra do grupo (B) apresentou porcentagem de pedúnculos de capítulos dentro do limite exigido pela Farmacopéia Brasileira 4a Ed. Os pedúnculos não contêm os constituintes ativos e a sua presença contribui para aumentar o peso. Excetuando uma única amostra pertencente ao grupo (B), todas as demais apresentaram teor de cinzas totais dentro do limite permitido de $14 \%$. No entanto, os valores apresentaram-se na faixa de 6,4 a 9,5\%, próximos aos encontrados por Batistic et al. (1989), quando analisaram amostras de camomila comercializadas em São Paulo. Estes resultados indicam uma necessidade de redução do limite máximo admitido pela farmacopéia brasileira, valor que permite adulterações.

A M. recutita é uma das poucas plantas medicinais cujos constituintes químicos foram exaustivamente aval iados farmacologicamente, inclusive em testes clínicos. A atividade antiinflamatória da droga deve-se à presença de óleos essenciais, ricos em azuleno, matricina e alfa-(-)-bisabolol, enquanto a atividade espasmolítica é atribuída à presença de grande concentração de flavonóides e outros constituintes fenólicos (Achterraht-Tuckermann et al., 1980; Ammon \& Kaul, 1992). No entanto, os constituintes ativos do óleo essencial só foram detectados em cerca de metade das amostras, em cada grupo. Matos et al. (1993) verificaram que a constituição do óleo essencial da camomila cultivada no Paraná era idêntica à daquela cultivada segundo os padrões europeus. A ausência destas substâncias nas amostras comerciais deve decorrer, portanto, de processos de produção e armazenagem inadequados. Por sua vez, os constituintes ativos fenólicos estiveram integralmente presentes em apenas $28,5 \%$ das amostras do grupo (A), $27,2 \%$ das amostras do grupo (B) e em nenhuma amostra do grupo (C).

Das 28 amostras analisadas, somente a finlandesa apresentou-se dentro dos padrões de qualidade exigidos pelos códigos oficiais e pela literatura. A falta de padronização e qualidade das amostras brasileiras, especialmente daquelas comercializadas pelas farmácias, comprometem a importância que esta e outras plantas medicinais possam representar na saúde pública brasileira, e confirmam a necessidade urgente da vigilância de fitoterápicos. 


\section{Agradecimentos}

As autoras agradecem ao Sr. Matti Kaalas da empresa Hankintatukku Oy (Helsinki, Finlândia) por ter gentilmente cedido a amostra européia, e ao CAPES, pelo apoio financeiro.

\section{Referências}

ACHTERRATH-TUCKERMANN, K. R.; FLASKAMP, E.; ISAAC, O. \& THIEMER, K., 1980. Pharmakologische Untersuchungen von Kamillen-Inhaltsstoffen. Planta Medica, 39:38-50.

AMMON, H. P. T. \& KAUL, R., 1992. Pharmakologie der kamille und ihrer Inhaltstoffe. Deutsche Apotheker Zeitung, 132(Sup.27):3-26.

BATISTIC, M. A.; AURICCHIO, M. T.; HOPPEN, V. R. \& YAMASHITA, I. Y., 1989. Verificação da qualidade e identidade de chás medicinais. Revista do Instituto Adolfo Lutz, 1:45-49.

BRITISH Pharmacopoeia, 1993. London: Her Majesty Stationery Office. 2v.

FARIAS, M. R.; SCHENKEL, E. P.; BERGOLD, A. M.; PETROVICK, P. R., 1985. O problema da qualidade dos fitoterápicos. Cadernos de Farmácia, 1:73-82.
FARMACOPÉIA Brasileira, 1959. 2ạ ed., São Paulo: Siqueira.

FARMACOPÉIA Brasileira, 1988-1996. 4ạ ed., São Paulo: Atheneu.

MATOS, F. J. A.; MACHADO, M. I. L.; ALENCAR, J. W. \& CRAVEIRO, A. A., 1993. Constituents of brazilian chamomile oil. Journal of Essential Oil Research, 5:337-339.

MS (Ministério da Saúde), 1995. Portaria no 6 de 31 de janeiro. São Paulo: Informativo SBF, mai/jun, 1995. Secretaria de Vigilância Sanitária.

STELLFELD, C., 1955. Da necessidade da regulamentação do comércio de plantas medicinais. Tribuna Farmacêutica, 22:185-189.

WAGNER, H.; BLADT, S. \& ZGAINSKI, E. M., 1984. Plant Drug Analysis. Berlin: Springer Verlag. 